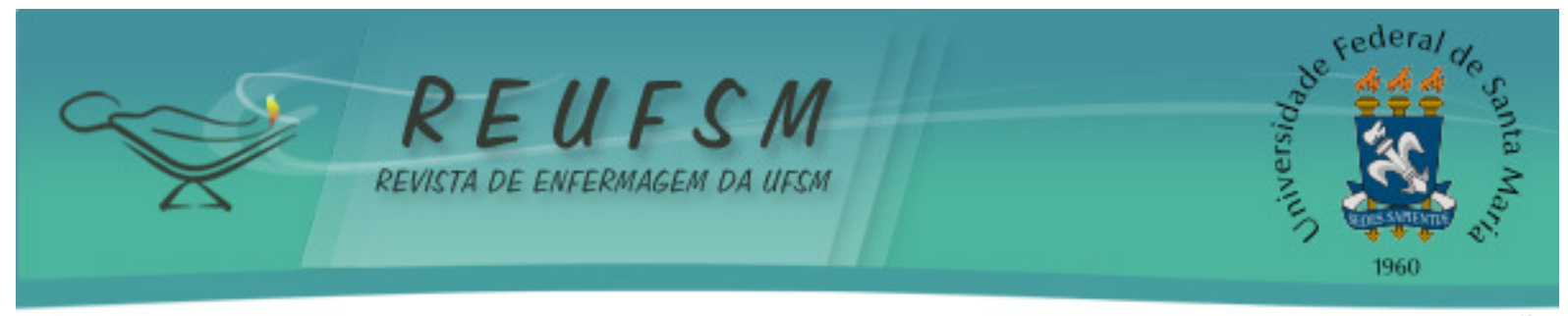

ARTIGO DE REFLEXÃO

\title{
CONHECIMENTO DE SI DO DOCENTE DA ÁREA DA SAÚDE: UMA REFLEXÃO EM FREIRE
}

\author{
SELF-KNOWLEDGE OF HEALTH TEACHERS: A FREIRE'S REFLECTION \\ EL AUTOCONOCIMIENTO DEL MAESTRO DEL ÁREA DE SALUD: UNA REFLEXIÓN BASADA \\ EN FREIRE
}

\author{
Bruna Pedroso Canever ${ }^{1}$ \\ Marta Lenise do Prado \\ Diana Coelho Gomes ${ }^{3}$ \\ Silvana Silveira Kempfer ${ }^{4}$
}

Doi: $10.5902 / 2179769213016$

RESUMO: Objetivo: reflexão teórica fundamentada em Freire sobre o conhecimento de si do docente da área da saúde. Método: estudo teórico-reflexivo. Resultados: o empoderamento dos educadores para o desenvolvimento da motivação, interação e sensibilidade possibilita a reflexão e a transformação do eu do docente e do meio em que está inserido. Considera-se o ato de conhecer-se essencial também para o aprofundamento da interdisciplinaridade, fornecendo assim subsídios para a transformação na formação superior na área da saúde. O conhecimento de si na relação pedagógica desperta, além da sensibilidade do docente, o sentimento amoroso, peça fundamental para mediar o processo educativo. Conclusão: a relevância do movimento de reflexão-ação-reflexão do docente sobre si mesmo pode auxiliar no processo de reconhecer-se e transformar-se, colaborando com uma formação diferenciada dos futuros profissionais de saúde.

Descritores: Docentes; Competência profissional; Prática profissional; Conhecimento; Enfermagem

ABSTRACT: Aim: reflection upon Freire's theory about the importance of health teacher's self-knowledge. Method: theoretical reflective study. Results: granting_educators the development of motivation, interaction and sensitivity enables a reflection and transformation of the teacher's self and of the environment in which the lecturer is. Selfknowledge is also essential to deepen interdisciplinarity, supporting transformation in graduation courses on health area. Pedagogically, self-knowledge awakens, besides the teacher's sensitivity, the feeling of love, essential to mediate the educational process. Conclusion: it is important that the teacher proceeds with a reflection - action-reflection about him or herself. It might help in the process of recognizing and transforming oneself, which collaborates with a differentiated training of future health professionals.

Descriptors: Faculty; Professional competence; Professional practice; Knowledge.

RESUMEN: Objetivo: reflexión teórica basada en Freire acerca del autoconocimiento del maestro de la salud. Método: estudio teórico y reflexivo. Resultados: empoderamiento de educadores para el desarrollo de la motivación, la interacción y sensibilidad,

\footnotetext{
${ }^{1}$ Enfermeira, Doutora em Enfermagem, Universidade Federal de Santa Catarina (UFSC), Florianópolis, Santa Catarina, Brasil, brunacanever@gmail.com

2 Enfermeira, Doutora em Enfermagem, Universidade Federal de Santa Catarina (UFSC), Florianópolis, Santa Catarina, Brasil, marta.lenise@ufsc.br

${ }^{3}$ Enfermeira, Mestre em Enfermagem, Universidade Federal de Santa Catarina (UFSC), Florianópolis, Santa Catarina, Brasil, dianacoelhog@gmail.com

${ }^{4}$ Enfermeira, Doutora em Enfermagem, Universidade Federal de Santa Catarina (UFSC), Florianópolis, Santa Catarina, Brasil, silvanakempfer@yahoo.com.br
} 


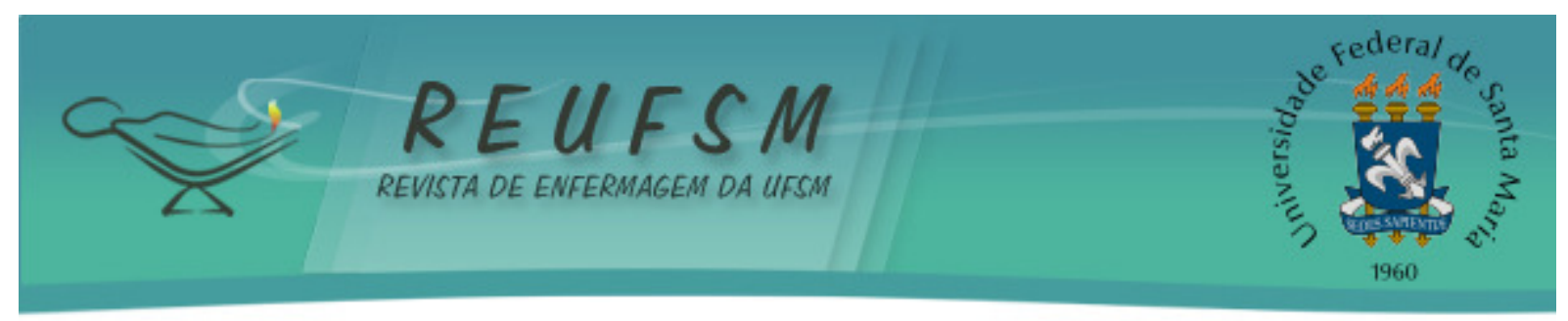

posibilitando la reflexión y transformación del yo docente y de su entorno. El autoconocimiento es esencial para profundizar la interdisciplinariedad, proporcionando subvenciones para la transformación de la educación superior en la salud. El conocimiento de sí mismo en la relación pedagógica despierta más allá de la sensibilidad del maestro, el sentimiento de amor, esencial para mediar el proceso educativo. Conclusión: la pertinencia del movimiento de reflexión-acción-reflexión del docente sobre sí mismo puede ayudar a reconocerse y convertirse, contribuyendo para una formación diferenciada de los futuros profesionales de la salud.

Descriptores: Docentes; Competencia profesional; Práctica profesional; Conocimiento.

\section{INTRODUÇÃO}

Este estudo tem como objetivo realizar uma reflexão teórica, fundamentada em Freire, sobre o conhecimento de si do docente da área da saúde. 0 ofício de ser docente é complexo, tem como premissa básica o ato de ensinar a partir do desenvolvimento de conteúdos teórico-práticos concretizados por meio de ações planejadas e orientadas pelo docente, na construção do conhecimento a ser desenvolvido pelos discentes.

O educador necessita estabelecer uma ação mediadora entre a formação do discente e sua cultura, a fim de proporcionar uma postura crítica e transformar a prática social. Não se pode compreender, numa sociedade em transição, uma educação que leve o homem a posições quietistas ao invés daquela que o leve à procura da verdade em comum, pois só é possível "compreender uma educação que fizesse do homem um ser cada vez mais consciente de sua transitividade, que deve ser usada tanto quanto possível criticamente, ou com aceno cada vez maior à racionalidade". 1:98

Nesse contexto, destaca-se o compromisso e o desafio do docente da área da saúde em formar profissionais crítico-criativos e reflexivos, para fazer frente às demandas profissionais, bem como ser capazes de atender aos princípios doutrinários do Sistema Único de Saúde (SUS). 0 docente da área da saúde precisa ser capaz de desenvolver em si características que atendam a esse tipo formação, ao longo de sua jornada acadêmica. Contudo, para que ele desenvolva uma educação libertária na sua prática pedagógica, são necessárias a valorização e a construção de saberes específicos, no início e ao longo da carreira docente, a fim de tornar o ambiente educativo um espaço curioso e criativo, possibilitando reflexão crítica em prol de ações que possam transformar a realidade. ${ }^{2}$

A partir do estabelecimento das Diretrizes Curriculares Nacionais (DCN) dos cursos da área da saúde ${ }^{3}$, potencializaram-se as discussões sobre a educação bancária e a transferência de conhecimento trazidas na obra de Freire, proporcionando espaço para um modelo educacional. Esse modelo enfatiza o discente como sujeito ativo, coparticipante de seu processo de aprendizagem, e o educador assume a postura de facilitador e orientador. Nessa perspectiva, as DCN possuem o desafio de orientar o ensino e o desenvolvimento de competências, habilidades e atitudes em uma nova perspectiva, na qual o discente precisa de uma postura autônoma, de empoderamento, para que possa instrumentalizar-se para a resolução de problemas com que se defrontará no dia a dia, aprender sobre a realidade social e reconhecer as fragilidades do seu conhecimento. Dessa forma, facilita-se a transformação da realidade em que o discente está imerso.

0 desenvolvimento das competências, habilidades e atitudes precisa ser pautado nas diretrizes do SUS, assim como fundamentado nos pilares da educação, a saber: aprender a conhecer, aprender a fazer, aprender a viver junto, aprender a conviver com os outros e aprender a ser. ${ }^{4}$ Em contrapartida, constata-se o conflito da atuação dos docentes da área da saúde em trabalhar com questões subjetivas no processo de aprendizagem, já que o modelo de ensino hegemônico avalia a objetividade como valor supremo, assim reduz e 


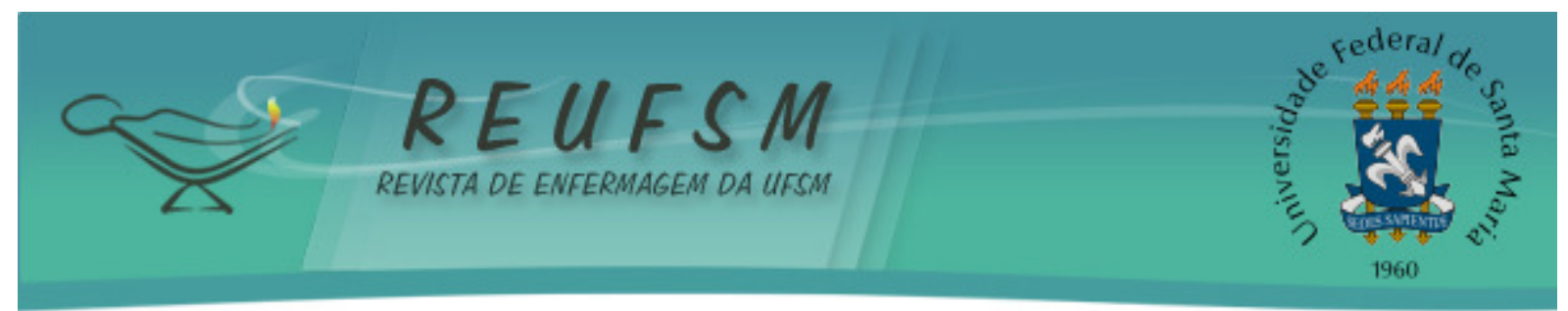

dicotomiza corpo e mente, razão e emoção. É importante que o docente desperte para sua autonomia, para o que pensa, suas crenças, seus valores e atitudes, e de que forma esses quesitos podem contribuir conscientemente com a formação profissional de outras pessoas.

A transformação na educação parte também da expressão de si dos docentes. Nesse sentido, "a educação, qualquer que seja o nível em que se vê, se fará tão mais verdadeira quanto mais estimule o desenvolvimento desta necessidade radical dos seres humanos, a de sua expressividade". ${ }^{2: 24}$ Para que ocorra mudança de paradigma nos modelos de ensino, é necessário que ocorra primeiramente uma mudança nos pensamentos e ideias do docente, ou seja, o docente precisa conhecer-se e reconhecer-se no mundo, ter consciência crítica sobre si, do todo e das partes, pois:

o todo tem qualidades ou propriedades que não são encontradas nas partes, se estas estiverem isoladas umas das outras, certas qualidades ou propriedades das partes podem ser inibidas pelas restrições provenientes do todo. É preciso efetivamente recompor o todo para conhecer as partes. ${ }^{6: 14}$

Nesse âmbito, refletir sobre o conhecimento de si do docente na área da saúde pode iluminar a discussão acerca do processo de formação na enfermagem, acreditando-se que, a partir do conhecimento de si, seja possível avançar em questões pertinentes à qualidade dessa formação docente, bem como no processo de aprendizagem e na relação pedagógica estabelecida entre os envolvidos nesse processo. Assim, aprofunda-se o conhecimento de si e se abrem possibilidades significativas na formação dos profissionais de saúde.

A partir disso, esta reflexão orienta-se por três caminhos interligados, descritos aqui separadamente, apenas por questões textuais: Conhecimento de si e a formação docente; Conhecimento de si no processo de aprendizagem; e Conhecimento de si na relação pedagógica.

\section{Conhecimento de si e a formação docente}

O homem é um ser em constante questionamento sobre si e seu mundo, e, nesse movimento reflexivo, busca compreender-se e compreender o outro como sujeito. Nesse sentido, "a reflexão e a tomada de consciência são meios pelos quais o homem busca conhecer-se, visivelmente como homem-sujeito e não como homem-objeto". 1:44

A formação docente nesse contexto constitui-se como um ciclo contínuo que envolve docente e discente, escola e comunidade, conhecimentos teóricos e experiências, proporcionando contínua transformação a quem ensina e a quem aprende. Dessa forma, não existe ensinar sem aprender, porque o ato de ensinar extrapola a simples necessidade do docente e seu aprendiz. Para concretizar-se o ato de ensinar, é necessária a constante troca de saberes, de tal maneira que quem ensina aprende, pois reconhece 0 conhecimento antes aprendido e observa a maneira como a curiosidade do discente trabalha para apreender e compreender. Assim, descobrem-se no ensinante incertezas, acertos e equívocos, durante o processo. ${ }^{7}$

Uma das questões fundamentais para a formação do docente em saúde é o conhecimento do seu eu, visto que o ato de conhecer-se tem pouca visibilidade e, por vezes, não é considerado na dimensão educativa. Como o conhecimento de si pode conduzir os docentes? Por que é tão importante percorrer o caminho para sua própria descoberta? 0 encontro do docente com o conhecimento de si permite também uma ampliação do olhar interdisciplinar, tão almejado na área da saúde, estabelecendo assim a 


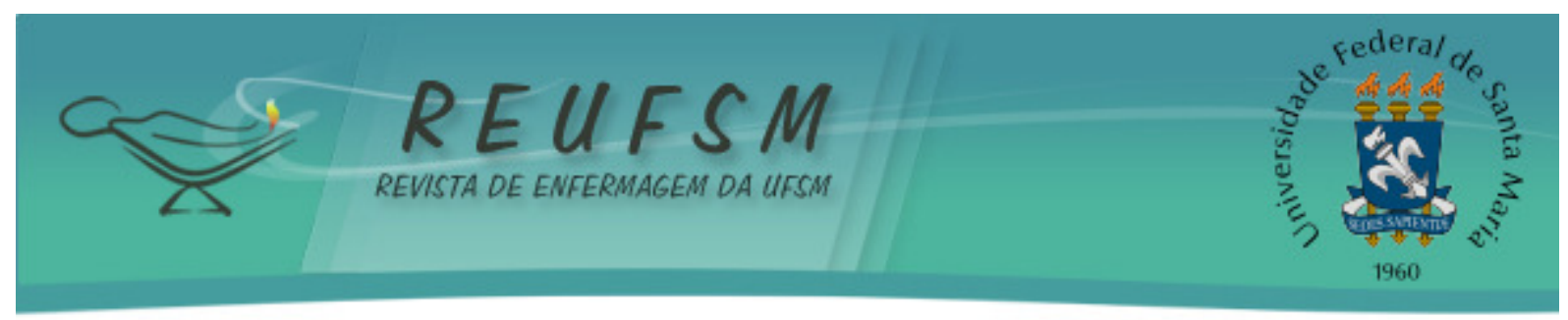

integração consigo, com seus discentes, com o ambiente de trabalho e com os profissionais de saúde, criando vínculos duradouros com a realidade. ${ }^{8}$

Outro fator que contribui com o conhecimento de si é o encontro com o outro, pois o ser-com configura-se nesse relacionar-se com o outro e com o mundo, destacando assim a importância da troca, da necessidade de ser em relação ao outro. Dessa forma, transformar-se é também mudar com o outro, com o meio, por meio de encontros e trocas, conhecer-se e se perceber, tendo a humildade de considerar o outro integralmente. ${ }^{9}$

Considera-se que a comunicação verbal, não verbal e corporal dos docentes sejam elementos intrínsecos e necessários para que os discentes possam compreender o sentido do conhecimento que os docentes pretendem construir e compartilhar. É importante lembrar a importância do conhecimento de si do docente sobre o próprio passado educacional, pois, por vezes, ele encontra obstáculos durante a comunicação com os discentes, o que revela uma possível educação emocional sem afeto no passado, a qual se reflete em práticas educacionais retrógradas e incompreensíveis no presente. ${ }^{10}$

Mas, o que significa conhecer-se para esse docente? Como o docente percebe isso? E por que se conhecer é um movimento complexo? Ora, para obter o conhecimento de si, o docente precisa mergulhar na própria condição humana, constituída por emaranhados de fios que exigem a compreensão de cuidar e entender os diversos aspectos que envolvem nossa constituição ao longo da evolução humana. ${ }^{8}$

Ressalta-se que, para além da concepção disciplinar, é importante que os discentes compreendam o que e como os docentes pensam e agem diante das práticas de profissionais, envolvendo também todo o contexto, uma vez que as crenças e os valores emitidos por eles constituem-se como peças fundamentais de aprendizagem na formação dos profissionais de saúde. Os educadores se configuram como formadores e transformadores de opiniões, por isso, torna-se fundamental que tenham consciência de que suas crenças e seus valores representam, muitas vezes, um espelho para os discentes, influenciando a forma como esses profissionais de saúde atuarão na sua prática. ${ }^{11}$

Compreender significa estar aberto às possibilidades que o mundo oferece. A partir da aproximação consigo e com o mundo, o ser compreende-se e, à medida que se lança no mundo, compreende e é compreendido. A compreensão sempre brota de si mesmo, “[...] porque o compreender sempre diz respeito a toda a abertura da presença como ser-nomundo. No compreender de mundo, o ser-em também é sempre compreendido. Compreender a existência como tal é sempre compreender o mundo [...]". 9:206-7

Nessa perspectiva, para a atuação competente do docente no ambiente educativo, é preciso que ele tenha amor pelo ambiente educacional em que está inserido, por sua profissão, por seus discentes e por si próprio, o qual também advém do conhecimento de si.

\section{Conhecimento de si e a prática pedagógica}

Vista de forma crítica, a prática pedagógica transporta o eixo conteudista para uma concepção complexa e dinâmica do processo de ensino-aprendizagem, englobando os envolvidos em um processo contínuo, instigante e integrador. Nessa perspectiva, torna-se necessária à ação educativa uma reflexão prévia sobre o homem e uma pré-analise sobre suas condições culturais, pois se considera o homem um "ser de raízes espaço-temporais", considera-se que a educação não existe fora das sociedades humanas e que não há homens isolados. 1:29

Para falar de conhecimento de si no processo educativo, é possível discorrer sobre o ato de conscientizar-se, acreditando que é "através da conscientização que os sujeitos assumem seu compromisso histórico no processo de fazer e refazer o mundo, dentro de possibilidades concretas, fazendo e refazendo a si mesmos". ${ }^{12: 99}$ A tomada de consciência do docente para o processo de aprendizagem torna-se um dos instrumentos mais valiosos, 


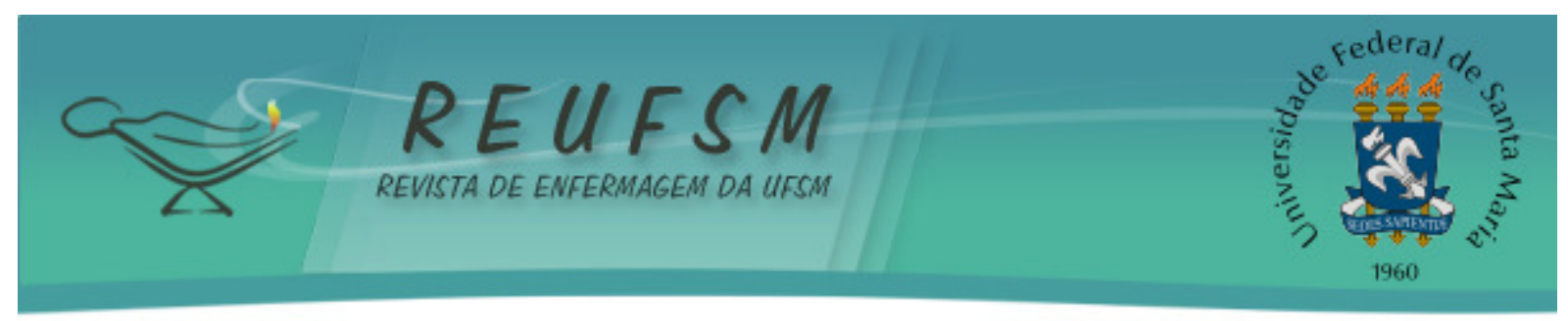

visto que pode auxiliar na transformação dos educandos, por meio da conscientização para a construção do conhecimento.

Existem dois tipos de consciência que podem estar presentes na atuação docente: a consciência ingênua e a epistemológica. A consciência ingênua se caracteriza por uma curiosidade de senso comum, do conhecimento empírico, impedindo o docente de desenvolver autonomia de si no processo de aprendizagem. Essa consciência só pode ser percebida, quando o docente tiver conhecimento de seu eu verdadeiro. Acredita-se que "a curiosidade epistemológica é construída pelo exercício crítico da capacidade de aprender". ${ }^{13: 27}$ Sendo assim, almeja-se que os docentes da área da saúde alcancem a consciência epistemológica, já que esta lhes permite tornar seu conhecimento e curiosidade mais rigorosos e sistematizados, superando a ingenuidade do conhecimento e propiciando que conheçam a si próprios e ao mundo de forma mais integral.

Nesse contexto, destaca-se que o conhecimento de si do docente no processo de aprendizagem ampliará as possibilidades de ações mais integradoras e totalizadoras, que englobem atividades para além da assimilação de conteúdos disciplinares, e também atividades que envolvam corpo e mente. Assim, desenvolve-se o conhecimento de si e a sensibilidade dos discentes, condição essencial para a formação e futura atuação profissional na área da saúde. ${ }^{14}$

Todas as experiências dos docentes, sejam afetivas ou de sentidos, permitem outra forma de conhecimento, além do intelectual: o sensível, conhecimento de si mesmo, do outro, do mundo ao nosso redor. Juntamente com todas as emoções vivenciadas e internalizadas, são trabalhados conhecimentos relacionados também a aspectos ecológicos, sociais, econômicos e culturais, conformando a ideia da integralidade do conhecimento do ser docente e discente no processo de aprendizagem.

Parece contraditório, se pensarmos que os docentes sempre estão em busca de palavras e ações que manifestem os reais motivos do conhecimento, sem muitas vezes pensar sobre sua razão sensível dentro do processo educativo. Nesse contexto, seria importante que reconhecessem a si próprios e compreendessem as sensações experienciadas, uma vez que tomar conhecimento de si significa compreender e reconhecer a dimensão corpo-espírito, físico e psicológico, potencialidades e fragilidades, que representam a unidade do ser no processo educativo. ${ }^{15}$ Considera-se ainda que, para que o ensino se torne realmente significativo, é fundamental que sejam considerados nesse processo educando e educador, com a consciência de si, amparados em suas crenças e seus valores.

Em relação a estar presente no processo educativo, considera-se que "o conhecimento exige uma presença curiosa do sujeito em face do mundo. Requer uma ação transformadora sobre a realidade. Demanda uma busca constante. Implica em invenção e em reinvenção". 7:48 Confirma-se, assim, que a presença do educador e educando são fundamentais nesse processo de ensino.

\section{Conhecimento de si na relação pedagógica}

Naturalmente, o homem é um ser de relações, vinculado espaço e temporalmente, reconhecidamente inacabado e sujeito de suas escolhas. Caminha na realidade com a realidade, a qual reconhece e na qual se reconhece ao caminhar. Esse movimento relacional nos distingue de outros seres, por sermos plurais, críticos e temporais, e termos consciência disso. Ainda, "a pluralidade destas relações dos homens e o mundo se caracteriza pelas descobertas do próprio mundo e de seu movimento nele". 1:62

O conhecimento de si que o docente precisa adquirir na relação pedagógica é importante para estabelecer a interação e o diálogo de forma amorosa, visto que se trata de profissionais que cuidarão de pessoas que se encontram em um momento delicado. É 


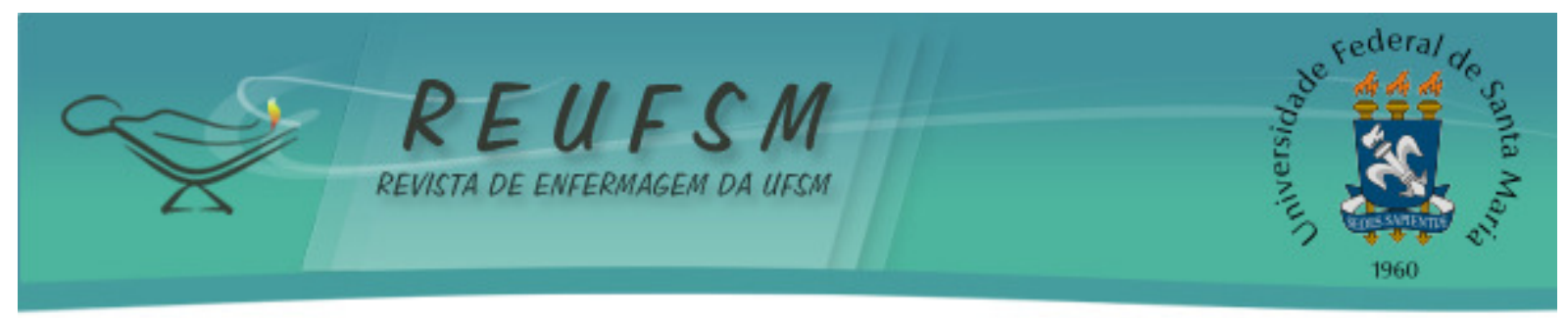

necessário que haja um espaço de troca de conhecimentos facilitado, de forma que o docente ensine a cuidar, demonstrando respeito, criatividade e sensibilidade. Destaca-se a relevância da abertura às inúmeras possibilidades no processo educativo, em que os docentes precisam oferecer aos discentes oportunidades para que alcancem a aprendizagem significativa, embasada na sensibilidade de estimular a integração, autonomia, discussão e curiosidade, contribuindo assim com o crescimento e a transformação da realidade de todos os envolvidos no processo. ${ }^{2}$

Como ser de relações, o homem, ao confrontar-se com o mundo, com sua realidade objetiva, toma consciência. Em consequência, ultrapassa "a mera apreensão da presença do fato", o que o coloca, "de forma crítica, num sistema de relações, dentro da totalidade em que se deu, e que, superando-se a si mesma, aprofundando-se, se tornou conscientização". 16:5353 Então, o docente, ao conhecer a si mesmo, na tomada de consciência, supera-se e empenha-se para conquistar a conscientização, que significa essa presença crítica do homem em sua realidade, desvelando-se não individual, mas coletivamente enquanto ser social. ${ }^{16}$

Conhecer-se implica gnosiologicamente conhecer o mundo e suas conexões e, em sentido pedagógico, há um movimento dialético envolvendo o educando e o educador como sujeitos cognoscentes. Essa característica é necessária para que ocorra o processo de conhecer e reconhecer de ambos, no qual "o educando vai conhecendo o ainda não conhecido e o educador, re-conhecendo o antes sabido". 1:79

A transformação que o docente vivencia dentro de si é justificada a partir de sua vivência histórica, considerando que aspectos emocionais eram pouco presentes na formação educacional tradicional, por não se tratar de conhecimento científico. 0 ser humano é considerado:

racional e irracional, capaz de medida e desmedida; sujeito de afetividade intensa e instável. [...] ansioso, angustiado, gozador, ébrio, extático; é um ser de violência e ternura, de amor e de ódio [...] nutre-se de conhecimentos comprovados, mas também de ilusões e quimeras. $6: 46$

Nesse contexto, a relação pedagógica amorosa em um espaço educativo é essencial. Um ambiente que proporciona vínculos de comprometimento, flexibilidade, motivação, confiança, respeito e empatia torna a aprendizagem um processo dialógico e horizontal, dando aos discentes a liberdade para que sejam participantes ativos na aprendizagem. ${ }^{10}$

A partir da reflexão do conhecimento de si na relação pedagógica, é possível o desenvolvimento no docente de uma consciência da sua prática, estabelecendo uma práxis de mudança do seu mundo educacional, movendo-se para um mundo mais sensível. Isso ocorre porque a relação pedagógica do docente é uma práxis específica que transforma a si mesmo e aos outros, pois "implica na intervenção da consciência, graças à qual o resultado existe duas vezes e em tempos diferentes: como resultado ideal e como produto real". 17:187 0 resultado ideal seria a consciência do docente no compromisso de formar profissionais críticos e reflexivos para o cuidado em saúde. Já o produto real pode sofrer algumas modificações, no sentido de que cada educando experimenta limites e avanços no decorrer da sua práxis evolutiva, os quais precisam ser considerados como oportunidades para o desenvolvimento de uma formação transformadora.

Quando os docentes conseguirem viver mais o momento presente, alcançam melhores habilidades para desenvolver a sensibilidade e intuição, fortalecendo 0 conhecimento integral. Isso lhes possibilita reconhecer seus limites, não como defeitos ou falhas, mas como algo que precisa ser trabalhado, no contexto e com humildade, partindo- 


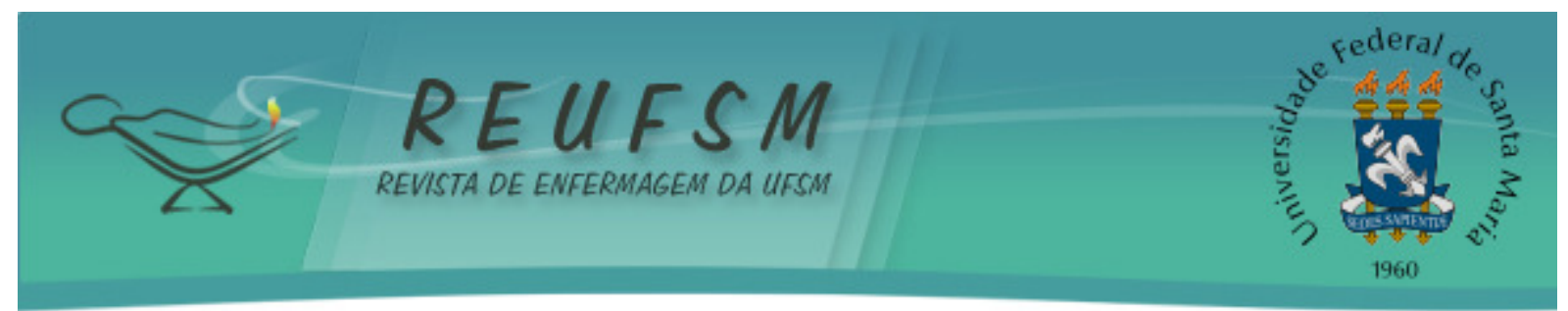

se do pressuposto de que todos somos seres inconclusos e inacabados e que as pessoas possuem diferentes capacidades. Aliás, são essas diversas capacidades que conformam a riqueza do conhecimento.

0 processo educativo ocorre verdadeiramente pelo fato de as pessoas serem sujeitos incompletos e por estarem em relação com o mundo e com as outras pessoas, completando-se durante toda a vida, por meio dos diferentes saberes trocados entre educandos e educadores. Entende-se que o conhecimento de si se configura em um processo complexo, que ocorre a partir da visão de cada um, de forma peculiar. A reflexão muitas vezes é lenta e precisa ocorrer cotidianamente, e todo esse movimento, também educacional, está imerso em um contexto sociocultural que é condicionante, mas não subordinado a ele. ${ }^{7}$

Por isso, o conhecimento de si na relação pedagógica exige um educador libertador, que efetivamente esteja com os educandos, em uma relação de troca de conhecimentos e sentimentos, que engloba o ser docente e sua inteireza. Nesse "ato conjunto de conhecimento, temos racionalidade e temos paixão. E isto é o que eu sou - um educador apaixonado - porque não entendo como viver sem paixão". 5:204 Assim, "o amor ao próximo, ao seu fazer, ao mundo, faz parte da vivência do educador", e quem não possui essa condição humana, "não é capaz de respeitar e compreender o outro, e não pode educar". 1:29

Dessa forma, acredita-se que o sentimento afetivo, como, por exemplo, o amor, é a base para a consciência e a transformação de si dos docentes, elemento importante para troca com o outro, para o crescimento e a sabedoria, sensibilidade e transformação. Sendo assim, "o cuidar de si neste momento expressa o compromisso para consigo". 18:145

\section{CONSIDERAÇÕES FINAIS}

Esta reflexão caminhou por três elementos importantes no processo de ensinoaprendizagem. São eles: o conhecimento de si e a formação docente; conhecimento de si no processo de aprendizagem; e o conhecimento de si na relação pedagógica.

No primeiro movimento de reflexão sobre o conhecimento de si e a formação docente, emerge como determinante para o processo de aprendizagem competente, na área da saúde, um conjunto de valores, crenças e conhecimentos de si do docente, bem como a integração, que emerge a partir do encontro do conhecimento de si e o saber.

Destaca-se também, no processo de ensino-aprendizagem, que o conhecimento de si proporciona aos docentes da área da saúde o desenvolvimento da reflexão-açãoreflexão, por meio de vivências cotidianas. Assim, oportuniza o questionamento, a expressão e o reencontro com um paradigma educacional agregador e consciente.

É preciso que os docentes consigam ouvir a si mesmos na relação pedagógica, por meio do pensamento, sentimento e reflexão, para sentirem-se amados, respeitados e valorizados, e tornarem-se protagonistas da sua própria história. A relevância do movimento de reflexão-ação-reflexão do docente sobre si pode auxiliá-lo no processo de reconhecer-se e transformar-se, bem como conhecer e transformar os discentes, colaborando também com uma formação diferenciada dos profissionais de saúde.

\section{REFERÊNCIAS}

1. Freire P. Educação como prática da liberdade. $29^{a}$ ed. Rio de Janeiro: Paz e Terra; 2006.

2. Prado ML, Reibnitz KS, Gelbcke FL. Aprendendo a cuidar: a sensibilidade como elemento plasmático para formação da profissional crítico-criativa em enfermagem. Texto \& Contexto Enferm. 2006;15(2):296-302. 
3. Brasil. Ministério da Educação. Conselho Nacional de Educação. Câmara de Educação Superior. Resolução CNE/CES N ${ }^{\circ} 1133$, de 1 de outubro de 2001. Diretrizes Curriculares para os cursos de graduação em enfermagem, medicina e nutrição [Internet]. [acesso em 2013 dez 20]. Disponível em: http://portal.mec.gov.br/dmdocuments/ces1133.pdf.

4. Corbellini VL, Santos BRL, Ojeda BS, Gerhart LM, Eidt OR, Stein SC, et al. Nexos e desafios na formação profissional do enfermeiro. Rev Bras Enferm. 2010;63(4):555-60.

5. Freire P. Ação cultural para a liberdade e outros escritos. $14^{\mathrm{a}}$ ed. Rio de Janeiro: Paz e Terra; 2011.

6. Morin E. Os sete saberes necessários a educação do futuro. $11^{\mathrm{a}}$ ed. São Paulo: Cortez; 2006.

7. Freire P. Pedagogia do oprimido. 50 ed. São Paulo: Paz e Terra; 2011.

8. Espírito Santo RC. Do autoconhecimento. Rev Interespe. 2010;1(0):1-3.

9. Heidegger M. Ser e tempo $3^{\mathrm{a}}$ ed. Petrópolis: Vozes; 2008.

10. Moran JM. A educação que desejamos: novos desafios e como chegar lá. $4^{a}$ ed. Campinas: Papirus; 2009. A afetividade na relação pedagógica; p.55-9.

11. Ronzani TM. A reforma curricular nos cursos de saúde: qual o papel das crenças? Rev Bras Educ Med. 2007;31(1):38-43.

12. Freire $P$. Conscientização: teoria e prática da libertação: uma introdução ao pensamento de Paulo Freire. $3^{\mathrm{a}}$ ed. São Paulo: Moraes; 1980.

13. Freire $P$. Pedagogia da autonomia: saberes necessários à prática educativa. $43^{\mathrm{a}}$ ed. São Paulo: Paz e Terra; 2011.

14. Andrade FR. Do simbólico. Rev Interespe. 2010;1(0):11-18.

15. Bertherat T, Bernstein C. O corpo tem suas razões. $21^{a}$ ed. São Paulo: Martins Fontes; 2010.

16. Freire P. Extensão ou comunicação. $10^{a}$ ed. Rio de Janeiro: Paz e Terra; 1977.

17. Vázquez AS. Filosofia da práxis. $2^{\mathrm{a}}$ ed. Rio de Janeiro: Expressão Popular; 2007.

18. Sebold LF, Kempfer SS, Carraro TE, Radünz V. Contribuições de encontros de sensibilização e cuidado para acadêmicos de enfermagem. Rev Enferm UFSM [Internet]. 2012 maio/ago [acesso em 2013 dez 20];2(2):386-93. Disponível em: http://cascavel.ufsm.br/revistas/ojs-2.2.2/index.php/reufsm/article/view/5319/3763.

Data de recebimento: $26 / 02 / 2014$

Data de aceite: 09/04/2015

Contato com autor responsável: Bruna Pedroso Canever

Endereço postal: Rua Jornalista Tito de Carvalho, 101 - Florianópolis (SC), CEP: 88040480.

E-mail: brunacanever@gmail.com 